\title{
Body mass index in young adulthood and cancer mortality: a retrospective cohort study
}

\author{
M Okasha, P McCarron, J McEwen, G Davey Smith
}

J Epidemiol Community Health 2002;56:780-784

\begin{abstract}
Study objective: To examine the relation between body mass index (BMI) in young adulthood and subsequent mortality from cancer.

Design: Cohort study.

Setting: University of Glasgow student health service. Weight and height were measured by a physician, and used to calculate BMI.

Participants: 8335 men and 2340 women who attended the student health service while at university between 1948 and 1968, and who were followed up with the NHS central register.

Main results: The main outcome measure was cancer mortality. Three hundred and thirty nine men and 82 women died of cancer during the follow up (mean 41 years). BMI was associated with mortality from all cancers in men and women, although it did not reach conventional statistical significance. The adjusted hazard ratio (HR) $(95 \% \mathrm{Cl})$ per $5 \mathrm{~kg} / \mathrm{m}^{2}$, was $1.22(0.97$ to 1.53$)$ in men and $1.43(0.95$ to 2.16) in women. Two hundred men and 61 women died from cancers not related to smoking. The adjusted HR for mortality from these were 1.36 (1.02 to 1.82$)$ and 1.80 (1.13 to 2.86$)$ respectively. These results are adjusted for height, number of siblings, pulse rate, year of birth, age, smoking, birth order, number of siblings, and age at menarche in women. Site specific analyses, comparing the highest with the lowest quartile of the BMI distribution found increased risks of prostate cancer $(n=28)$ and breast cancer among heavier subjects. No association between BMI and colorectal cancer was found. Conclusions: $\mathrm{BMI}$ in adolescence has lasting implications for risk of cancer mortality in later life. Future research will include measures of BMI throughout the lifecourse, to determine the period of greatest risk of obesity, in terms of cancer mortality.
\end{abstract}

See end of article for authors' affiliations

Correspondence to: Dr M Okasha, Department of Social Medicine, University of Bristol Canynge Hall, Whiteladies Road, Bristol, UK

Mona.Okasha@bristol.ac.uk

Accepted for publication 11 February 2002
A the prevalence of adult obesity continues to rise, ${ }^{12}$ the risks of weight related morbidity and mortality are likely to increase. Increasing obesity among adolescents and young adults also poses serious health risks. Body mass index (BMI) in early adult life is directly associated with all cause $^{34}$ and cardiovascular disease mortality. ${ }^{5}$ Results from studies of the relation between early life BMI and cancer risk have been inconsistent. This may be attributable in part to the reliance by some authors on recalled adolescent weight. Differential misreporting across the weight spectrum may bias studies based on recalled measures. ${ }^{6}$ Recalled weight may also be influenced by current weight and so may reflect current measures more closely than is actually the case.

Cancer risk has been described in three cohorts with early life weight measures. Among Harvard and Pennsylvania University alumni, BMI at age 18 was weakly associated with risk of colon cancer in men $^{7}$ and breast cancer in women. ${ }^{8}$ In the Harvard growth study, overweight adolescent men had a higher risk of colon cancer mortality than lean men, but adolescent BMI was unrelated to any cancer in women. ${ }^{9}$ However, in this study only four women died of colorectal cancer and eight of breast cancer. Among the 1932 Dutch birth cohort, the higher cancer mortality in leaner men was explained by the inverse relation between BMI and lung cancer. ${ }^{10}$ This relation may be confounded by smoking, as smokers are at increased risk of lung cancer but may be leaner than non-smokers. Classifying cancers according to their relation to smoking can overcome the difficulty of not knowing individuals' smoking patterns throughout life.

We report here on the association between measures of adolescent BMI and subsequent cancer mortality over 40 years in a cohort of alumni from the University of Glasgow.

\section{METHODS}

In 1948, the University of Glasgow initiated annual health checks at the university health service, which all students were invited to attend. Detailed sociodemographic and behavioural data were obtained from a physician completed questionnaire, and height and weight measurements were made. The students who attended between 1948 and 1968 comprise the Glasgow Alumni Cohort, described in detail elsewhere. ${ }^{11}$ The cohort members are flagged at the NHS central register (NHSCR) and we are notified of deaths.

The current study comprises follow up to 30 September 1999. Cause of death determined from the death certificate was coded using the International Classification of Disease, ninth revision (ICD9). We included all malignant neoplasms, but excluded those of "uncertain behaviour" and carcinomas in situ. Analyses were conducted for all cancers, and cancer subgroups, according to their relation to smoking (that is, those thought to be related to smoking and those not thought to be related to smoking). Cancers related to smoking are: oropharynx, oesophagus, pancreas, respiratory, and urinary tracts (ICD9 codes 1400-1509; 1570-1579; 1600-1639; 1650-1659; 1880-1899). The remainder were classified as cancers not related to smoking. ${ }^{12}$ Site specific analyses were conducted for the most common cancers not thought to be related to smoking (that is, prostate and colorectal cancer in men, breast cancer in women).

\section{Statistical methods}

BMI and mortality were modelled using Cox regression, with age as the time dependent variable. The proportional hazard

Abbreviations: $B M I$, body mass index; HR, hazard ratio 


\begin{tabular}{|c|c|c|c|c|c|}
\hline & Q1 & Q2 & Q3 & Q4 & $\begin{array}{l}\text { p Value } \\
\text { (heterogeneity) }\end{array}$ \\
\hline \multicolumn{6}{|l|}{ Men } \\
\hline Mean BMI $\left(\mathrm{kg} / \mathrm{m}^{2}\right)$ & 19.02 & 20.81 & 22.15 & 24.67 & \\
\hline BMI range $\left(\mathrm{kg} / \mathrm{m}^{2}\right)$ & $13.28-20.13$ & $20.14-21.47$ & $21.48-22.92$ & $22.93-36.20$ & \\
\hline $\mathrm{n}(\%)$ & $2116(25.4 \%)$ & $2105(25.2 \%)$ & $2092(25.1 \%)$ & $2022(24.3 \%)$ & \\
\hline Age $(y)$ & $20.47(3.13)$ & $20.70(3.36)$ & $20.99(3.61)$ & $22.35(5.33)$ & $<0.001$ \\
\hline Height $(\mathrm{cm})$ & $175.17(6.30)$ & $175.19(5.96)$ & $174.68(6.20)$ & $173.91(6.80)$ & $<0.001$ \\
\hline Weight $(\mathrm{kg})$ & $58.43(4.94)$ & $63.97(4.48)$ & $67.66(4.90)$ & $74.70(7.63)$ & $<0.001$ \\
\hline Number of siblings & $1.40(1.01)$ & $1.50(1.01)$ & $1.54(1.03)$ & $1.56(1.05)$ & $<0.001$ \\
\hline Pulse rate (beats/min) & $76.59(10.61)$ & $75.23(9.78)$ & $75.09(10.41)$ & $74.92(10.53)$ & $<0.001$ \\
\hline Social class I/II (\%) & 54.96 & 56.86 & 54.92 & 55.93 & 0.54 \\
\hline First born (\%) & 57.84 & 54.77 & 53.54 & 52.08 & 0.002 \\
\hline Smoker (\%) & 35.49 & 34.16 & 32.70 & 34.62 & 0.28 \\
\hline \multicolumn{6}{|l|}{ Women } \\
\hline Mean BMI $\left(\mathrm{kg} / \mathrm{m}^{2}\right)$ & 18.59 & 20.43 & 21.90 & 24.53 & \\
\hline BMI range $\left(\mathrm{kg} / \mathrm{m}^{2}\right)$ & $11.77-19.71$ & $19.72-21.11$ & $21.12-22.79$ & $22.80-35.08$ & \\
\hline $\mathrm{n}(\%)$ & $595(25.4)$ & $581(24.8)$ & $585(25.0)$ & $579(24.8)$ & \\
\hline Age $(y)$ & 19.54 (2.69) & $19.49(2.67)$ & $19.56(2.79)$ & $19.97(3.90)$ & 0.027 \\
\hline Height $(\mathrm{cm})$ & $163.68(5.77)$ & $163.16(5.56)$ & $163.21(5.53)$ & $162.63(6.12)$ & 0.019 \\
\hline Weight (kg) & $49.88(4.51)$ & $54.44(3.83)$ & $58.41(4.05)$ & $64.94(6.43)$ & $<0.001$ \\
\hline Number of siblings & $1.29(0.97)$ & $1.45(1.00)$ & $1.43(0.99)$ & $1.43(1.04)$ & 0.017 \\
\hline Pulse rate (beats/min) & 78.67 (11.05) & $76.69(8.90)$ & $76.52(9.45)$ & $77.13(9.36)$ & 0.001 \\
\hline Age at menarche & $13.19(1.28)$ & $13.07(1.24)$ & $12.93(1.23)$ & $12.74(1.20)$ & $<0.001$ \\
\hline Social class I/II (\%) & 61.01 & 63.34 & 60.00 & 60.45 & 0.66 \\
\hline First born (\%) & 66.55 & 60.07 & 59.66 & 57.69 & 0.011 \\
\hline Smoker (\%) & 19.33 & 18.07 & 20.51 & 23.14 & 0.17 \\
\hline
\end{tabular}

assumptions underlying these models were tested. All models were adjusted for year of birth to account for possible cohort effects. Hazard ratios (HR) were calculated per quartile of BMI for each sex, using the lowest quartile as the baseline category. To investigate a linear relation between BMI and mortality, HR per $5 \mathrm{~kg} / \mathrm{m}^{2}$ were calculated. We also investigated the relation between overweight (BMI $>25 \mathrm{~kg} / \mathrm{m}^{2}$ ) and cancer mortality.

Potential confounders included in fully adjusted models were: height (sex specific quartiles); childhood social class (I to IV/V); birth order $(1,2,3,4+)$; number of siblings $(0,1,2,3+)$; smoking (yes, no); pulse rate; age at menarche in women $(\leqslant 11,12-13,14+$ years $)$. Each of these measures was self reported at the student health service. Therefore, the measures of smoking and pulse rate relate to the factors in early adulthood. No data on adulthood measures were available. Because of small numbers, social classes IV and V were combined. All analyses were performed using STATA (version 6.0).

\section{RESULTS}

Of the 15322 students who attended the student health service, we have traced $12553(82 \%)$ through the NHSCR. Of these, 393 who had no record of when they left the UK or entered the armed forces were excluded. Eighty with missing anthropometric values or unknown date of death $(\mathrm{n}=2)$ were also excluded. There was no difference in the association between BMI and all cause mortality among those participants with complete data on potential confounders and the total cohort. This justified the exclusion of participants with

Table 2 Hazard ratios (95\% confidence intervals) per quartile of BMI (Q1-4) and per $5 \mathrm{~kg} / \mathrm{m}^{2}$ for all cause and cancer mortality

\begin{tabular}{|c|c|c|c|c|c|c|}
\hline & \multicolumn{3}{|c|}{ All causes } & \multicolumn{3}{|c|}{ All cancers } \\
\hline & $\begin{array}{l}\text { No. of } \\
\text { deaths }\end{array}$ & $\begin{array}{l}\text { Hazard ratio (adj. for } \\
\text { year of birth) }\end{array}$ & $\begin{array}{l}\text { Hazard ratio (fully } \\
\text { adjusted)* }\end{array}$ & $\begin{array}{l}\text { No. of } \\
\text { deaths }\end{array}$ & $\begin{array}{l}\text { Hazard ratio (adj. for } \\
\text { year of birth) }\end{array}$ & $\begin{array}{l}\text { Hazard ratio (fully } \\
\text { adjusted)* }\end{array}$ \\
\hline \multicolumn{7}{|l|}{ Males } \\
\hline Q1† & 233 & 1.0 & 1.0 & 80 & 1.0 & 1.0 \\
\hline Q2 & 221 & $0.93(0.78$ to 1.12$)$ & 0.95 (0.79 to 1.14$)$ & 83 & $1.03(0.76$ to 1.40$)$ & $1.04(0.76$ to 1.41$)$ \\
\hline Q3 & 228 & $0.96(0.80$ to 1.16$)$ & $0.97(0.81$ to 1.17$)$ & 77 & $0.96(0.70$ to 1.31$)$ & $0.96(0.70$ to 1.32$)$ \\
\hline Q4 & 289 & $1.08(0.91$ to 1.19$)$ & $1.10(0.92$ to 1.32$)$ & 99 & $1.12(0.83$ to 1.51$)$ & $1.14(0.84$ to 1.54$)$ \\
\hline$P($ trend $) \ddagger$ & & 0.31 & 0.24 & & 0.55 & 0.48 \\
\hline Per $5 \mathrm{~kg} / \mathrm{m}^{2}$ & 971 & $1.16(1.02$ to 1.33$)$ & $1.18(1.03$ to 1.35$)$ & 339 & 1.20 (0.96 to 2.50$)$ & $1.22(0.97$ to 1.53$)$ \\
\hline$P($ trend $) \S$ & & 0.027 & 0.015 & & 0.12 & 0.090 \\
\hline \multicolumn{7}{|l|}{ Females } \\
\hline Q1† & 27 & 1.0 & 1.0 & 14 & 1.0 & 1.0 \\
\hline Q2 & 31 & $1.22(0.73$ to 2.25$)$ & $1.31(0.78$ to 2.21$)$ & 19 & $1.43(0.72$ to 2.85$)$ & $1.53(0.76$ to 3.07$)$ \\
\hline Q3 & 35 & $1.28(0.77$ to 2.12$)$ & $1.37(0.83$ to 2.29$)$ & 25 & 1.80 (0.93 to 3.46$)$ & $1.94(1.00$ to 3.75$)$ \\
\hline Q4 & 45 & $1.58(0.98$ to 2.55$)$ & 1.64 (1.01 to 2.67$)$ & 24 & $1.68(0.87$ to 3.25$)$ & 1.79 (0.92 to 3.49$)$ \\
\hline$P($ trend $) \ddagger$ & & 0.061 & 0.050 & & 0.098 & 0.069 \\
\hline Per $5 \mathrm{~kg} / \mathrm{m}^{2}$ & 138 & 1.31 (0.95 to 1.79$)$ & 1.31 (0.96 to 1.80$)$ & 82 & $1.39(0.92$ to 2.10$)$ & $1.43(0.95$ to 2.16$)$ \\
\hline$P($ trend $) \S$ & & 0.10 & 0.096 & & 0.13 & 0.098 \\
\hline
\end{tabular}

*Adjusted for height, number of siblings, pulse rate, birth order and smoking and for age in menarche in females. †Reference category. $\ddagger$ Trend over quartiles of BMI. §Trend per $\mathrm{kg} / \mathrm{m}^{2}$ of BMI. 
Table 3 Hazard ratios (95\% confidence intervals) per quartile of $B M I(Q 1-4)$ and per $5 \mathrm{~kg} / \mathrm{m}^{2}$ for smoking and non-smoking related cancer mortality

\begin{tabular}{|c|c|c|c|c|c|c|}
\hline & \multicolumn{3}{|c|}{ Cancers related to smoking } & \multicolumn{3}{|c|}{ Cancers not related to smoking } \\
\hline & $\begin{array}{l}\text { No. of } \\
\text { deaths }\end{array}$ & $\begin{array}{l}\text { Hazard ratio (adj. for } \\
\text { year of birth) }\end{array}$ & $\begin{array}{l}\text { Hazard ratio (fully } \\
\text { adjusted)* }\end{array}$ & $\begin{array}{l}\text { No. of } \\
\text { deaths }\end{array}$ & $\begin{array}{l}\text { Hazard ratio (adj. for } \\
\text { year of birth) }\end{array}$ & $\begin{array}{l}\text { Hazard ratio (fully } \\
\text { adjusted)* }\end{array}$ \\
\hline \multicolumn{7}{|l|}{ Males } \\
\hline Q1† & 36 & 1.0 & 1.0 & 44 & 1.0 & 1.0 \\
\hline Q2 & 36 & $0.98(0.62$ to 1.56$)$ & 1.01 (0.64 to 1.61$)$ & 47 & $1.06(0.70$ to 1.60$)$ & $1.06(0.70$ to 1.60$)$ \\
\hline Q3 & 31 & 0.85 (0.53 to 1.38$)$ & 0.87 (0.54 to 1.42 ) & 46 & $1.04(0.69$ to 1.57$)$ & $1.04(0.68$ to 1.57$)$ \\
\hline Q4 & 36 & 0.87 (0.54 to 1.39$)$ & $0.90(0.57$ to 1.46$)$ & 63 & $1.33(0.90$ to 1.96$)$ & $1.33(0.90$ to 1.96$)$ \\
\hline$P($ trend $) \ddagger$ & & 0.46 & 0.58 & & 0.17 & 0.17 \\
\hline Per $5 \mathrm{~kg} / \mathrm{m}^{2}$ & 139 & $0.99(0.69$ to 1.41$)$ & 1.03 (0.72 to 1.48$)$ & 200 & $1.36(1.02$ to 1.81$)$ & $1.36(1.02$ to 1.82$)$ \\
\hline$P($ trend $) \S$ & & 0.94 & 0.87 & & 0.039 & 0.039 \\
\hline \multicolumn{7}{|l|}{ Females } \\
\hline Q1† & 6 & 1.0 & 1.0 & 8 & 1.0 & 1.0 \\
\hline Q2 & 4 & $0.70(0.20$ to 2.48$)$ & 0.85 (0.24 to 3.07$)$ & 15 & $1.98(0.84$ to 4.66$)$ & 2.05 (0.86 to 4.88$)$ \\
\hline Q3 & 7 & 1.11 (0.37 to 3.31$)$ & 1.33 (0.44 to 4.03$)$ & 18 & $2.31(1.00$ to 5.30$)$ & 2.41 (1.04 to 5.57$)$ \\
\hline Q4 & 4 & $0.59(0.17$ to 2.11$)$ & $0.67(0.18$ to 2.43$)$ & 20 & $2.52(1.11$ to 5.73$)$ & 2.62 (1.14 to 6.01$)$ \\
\hline $\mathrm{P}($ trend $) \ddagger$ & & 0.60 & 0.75 & & 0.026 & 0.023 \\
\hline Per $5 \mathrm{~kg} / \mathrm{m}^{2}$ & 21 & $0.66(0.28$ to 1.59$)$ & $0.71(0.31$ to 1.67$)$ & 61 & 1.77 (1.11 to 2.80$)$ & 1.80 (1.13 to 2.86$)$ \\
\hline$P($ trend $) \S$ & & 0.35 & 0.43 & & 0.020 & 0.018 \\
\hline
\end{tabular}

*Adjusted for height, number of siblings, pulse rate, birth order and smoking and for age in menarche in females. †Reference category. $\ddagger$ Trend over quartiles of BMI. §Trend per $\mathrm{kg} / \mathrm{m}^{2}$ of BMI.

missing data $(n=1403)$ from subsequent analyses. The remaining dataset comprises 8335 men and 2340 women.

Table 1 shows the characteristics of the cohort members. Higher BMI was directly associated with being older. Participants in the top BMI quartile tended to have more siblings and were less likely to be first born. Pulse rate and age at menarche were inversely associated with BMI. Smoking was more common in higher social classes; the proportion of smokers in social classes I/II was 33\% compared with $29 \%$ in classes III-V $(\mathrm{p}<0.001)$.

Mean follow up time was 41 years. During this time, 971 men ( $11.7 \%)$ and 138 women (5.9\%) died. Of these, 339 men $(35 \%)$ and 82 women (59\%) died of cancer. The results shown in table 2 suggest an association between adolescent BMI and all cause mortality in men and women. The increased risk seems to be restricted to the upper quartile of BMI in men, whereas in women the relation seems linear. The association between BMI and cancer mortality appears positive in both sexes, but does not reach conventional statistical significance.

No relation was found between BMI and smoking related cancer mortality in either sex, as shown in table 3. Of all the cancer deaths, 200 men (59\%) and 61 women (74\%) died of cancers not related to smoking. For mortality from these cancers, a positive association with BMI was found in both sexes. As with all cause mortality, the relation in men seems to be restricted to the top BMI quartile, whereas the relation in women is more linear. Furthermore, the magnitude of the relation is much greater in women than men. These differences are apparent in figure 1.

Few people were obese in young adulthood (45 men, 8 women), so this precluded studying obesity in relation to cancer. Comparisons were made of the risk of cancer in people who were overweight in young adulthood with those at the lower end of the "normal" BMI range (that is, $\geqslant 25 \mathrm{~kg} / \mathrm{m}^{2}$ versus $\left.20-22 \mathrm{~kg} / \mathrm{m}^{2}\right)$. This analysis included 745 overweight men and 186 overweight women. For smoking related cancers, there was no association between overweight in young adulthood and cancer risk (OR: 1.17, 95\%CI: 0.67 to 2.03 in men; OR: 0.75 95\%CI: 0.15 to 3.69 in women). For cancers not thought to be related to smoking, there was indication of a positive association between overweight and cancer risk, although these results did not reach conventional levels of statistical significance (OR: 1.46, 95\%CI: 0.93 to 2.32 in men; OR: $1.4695 \%$ CI: 0.66 to 3.25 in women).

Site specific analyses were performed, comparing the highest with the lowest quartile of the BMI distribution. The OR

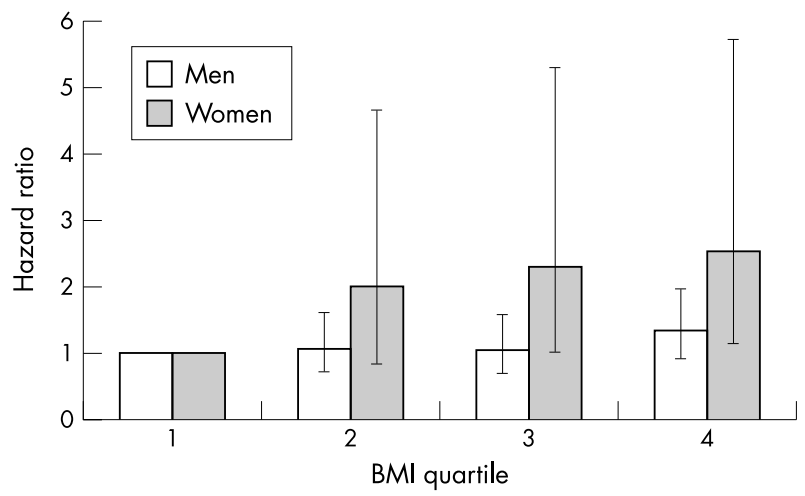

Figure 1 Asociation between BMl and mortality from cancers not thought to be related to smoking.

for death from prostate cancer $(\mathrm{n}=28)$ was 1.49 (0.54 to 4.12$)$. The OR for death from colorectal cancer among men $(n=64)$ was 0.98 (0.47 to 2.05). The OR for death from breast cancer among women $(\mathrm{n}=32)$ was 3.61 ( 1.00 to 12.94$)$.

Comparing crude and adjusted results in tables 2 and 3, it is clear that the confounding variables studied made no appreciable difference to the parameter estimates. Neither did further adjustment for alcohol intake affect the magnitude of the associations (results not shown). Tests of interaction were conducted to investigate whether the relation between BMI and mortality were modified by either social class or smoking. No evidence for an interaction was found, although the numbers of deaths may be too small to detect significant effect modification (results not shown).

\section{DISCUSSION}

The results from this study provide evidence for a positive association between BMI in young adulthood and mortality in later life. Each $5 \mathrm{~kg} / \mathrm{m}^{2}$ was associated with increased hazard for all cause mortality of approximately $20 \%$ in men $(p=0.015)$ and $30 \%$ in women $(p=0.096)$. For mortality from cancers unrelated to smoking, the increased hazard per 5 $\mathrm{kg} / \mathrm{m}^{2}$ was almost $40 \%$ in men $(\mathrm{p}=0.039)$ and $80 \%$ in women $(p=0.018)$. No alternative explanations for the detected associations by factors measured in the study are apparent. 


\section{Strengths and limitations}

The main strength of this study is that it is based on a large cohort, whose members had height and weight measured in early life. Cohort members have been followed up over a considerable period of time and few emigrated.

The primary limitation of the study is the select population, and the external validity of this study to a current group of young adults must be considered. The students were from relatively affluent backgrounds, with over half from families in social class I or II. The patterns of overweight and obesity differ from recent figures obtained from the Scottish Health Survey, $1995 .{ }^{12}$ In that study, in the age range 16 to $24,4.5 \%$ of men and $9 \%$ of women were obese (BMI $\left.>30 \mathrm{~kg} / \mathrm{m}^{2}\right)$, compared with $0.5 \%$ and $0.3 \%$ among Glasgow students. Increasing obesity in recent decades does not explain the gender differences seen between Glasgow students and current figures. Furthermore, the health behaviours of the students do not reflect current patterns within the general population. For example, smoking among the Glasgow students was more prevalent in those from higher social classes, whereas in the 1995 Scottish Health Survey the converse was true. ${ }^{13}$ However, in our study there was no evidence of effect modification by smoking or social class, suggesting that the generalisability of the results is unlikely to be undermined by the selectivity of the cohort.

A second possible selection bias in the study is the exclusion of those students for whom data were missing. There were few with missing anthropometric measures, so our primary concern is those with missing data on potential confounding variables. Their exclusion made no difference to the magnitude of the effect estimates, nor did controlling for any of the potential confounding factors, among those participants who had these data recorded, change the magnitude of the crude hazard ratio. Our findings are therefore unlikely to be biased due to the exclusion of cohort members with missing data.

Thirdly, the potential confounders used in our study were limited in number and timing. We have no data on dietary intake in young adulthood, and physical activity was crudely approximated by the use of pulse rate. Furthermore, the measures of health behaviours used (smoking and alcohol intake) were made at one point in time in young adulthood. Therefore confounding by these behaviours throughout adult life cannot be ruled out as an explanation of our results.

Finally, despite the large size of this cohort, the number of events, particularly among women, is small. This reduces the ability of the study to detect differences in risks between groups. Further analyses in the future, with more detailed follow up data (self reported morbidities and hospital admissions), will permit more weight to be placed on the observed results.

\section{Comparison with previous work}

Results from the three large cohort studies that have measures of adolescent BMI differ in their results. ${ }^{7810}$ Among the 1932 Dutch male birth cohort, the only significant association between BMI at age 18 years and site specific cancer mortality over the subsequent 32 years was an inverse relation of BMI with lung cancer mortality. ${ }^{10}$ These results were not controlled for smoking, which may be an important confounder in this relation. Among alumni from Harvard and Pennsylvania University, relative weight in young adulthood was associated with breast cancer. ${ }^{8}$ Interestingly, no association was seen between relative weight at an intermediate follow up (when the women were aged approximately 30 years). These are consistent with our results, in which the strongest risk detected was the association between BMI and mortality from breast cancer. In the Harvard Growth Study, men but not women who had been overweight in adolescence had an increased risk of colorectal cancer mortality compared with those who had been lean, although the confidence intervals for the risk estimate were wide. ${ }^{9}$ Our results found no evidence to support the

\section{Key points}

- $\mathrm{BMI}$ in young adulthood is related to cancer mortality in later life.

- This is particularly evident for breast cancer mortality

- A possible mediator of the association between BMI and cancer mortality is insulin-like growth factor 1 (IGF-1)

- The role of weight patterns and fluctuations throughout the life course needs to be explored in relation to cancer risk

- Biological mediators underlying these associations also deserve exploration

presence of an association between BMI and colorectal cancer mortality in men. The lack of association between BMI and breast cancer detected in the Harvard Growth Study may be attributable to the small number of deaths from this cause $(\mathrm{n}=8)$ in that cohort.

Our results, and those from the female alumni of Pennsylvania university ${ }^{8}$ of the relation between BMI at age 18 and breast cancer risk, are inconsistent with results from three large cohort studies. Among women in the Nurses' Health Study, the Iowa Women's Health Study, and the Netherlands' Cohort Study, inverse relations were seen between recalled BMI at age 18 to 20 and breast cancer risk. ${ }^{14-16}$ As well as relying on recalled weight in adolescence, both these studies used incident cancers as an outcome, whereas cancer mortality was used in the two alumni studies. If BMI is associated with poor survival from breast cancer, differences in the BMI-breast cancer relation will be observed depending on the outcome studied. The follow up phase of the Glasgow Alumni Cohort will permit comparison of results in the same cohort of BMI with incidence and mortality. We were unable to differentiate between pre-menopausal and post-menopausal breast cancer in our study, as our outcome data relied on death certificates. However, this distinction ought to be made in future work, and will be available for the study of incident cancers in the Glasgow Alumni Cohort.

\section{Disease pathways}

Three pathways exist through which early life BMI could affect adult disease, each distinct in terms of its dependence on adult life measures. Firstly, the association may be independent of adult measures of obesity, and may be a result of early life programming. Intrauterine exposure to maternal oestrogens may create a setting suitable for the initiation and development of breast cancers. ${ }^{17}$ Hormonal changes associated with overweight in childhood and adolescence may form a similar environment conducive to carcinogenesis. Secondly, the risk associated with early life BMI may operate solely through adult life measures. Among 1085 Glasgow students who were asked to report their weight 15 years after their initial health check, ${ }^{18}$ significant tracking of BMI occurred, $r=0.65$ (men) and $r=0.47$ (women). However, the results from the female alumni of Pennsylvania University described above are not consistent with the hypothesis that cancer risk associated with adolescent BMI is solely dependent on adult BMI. ${ }^{8}$ Thirdly, the association of cancer risk with BMI in early adulthood may reflect a trajectory of events set by exposures in early life. In this model, the accumulation of risk over a lifetime could affect adult health. Although with the current dataset we cannot confirm this, we suggest that this model of risk accumulation throughout life is the most plausible of our results.

\section{Biological mechanisms}

Animal experiments have demonstrated that high energy intake is associated with increased cancer risk. ${ }^{19}$ Results from a large prospective cohort demonstrate that energy intake in early childhood is associated with increased risk of cancer 
mortality. ${ }^{20}$ Although in this study we have no measure of energy intake or physical activity, high BMI is a marker of higher energy intake to expenditure ratio. Frankel and colleagues suggest that reduced energy intake could minimise carcinogenesis through lowering cell proliferation during development, thus lowering the chances of carcinogenic mutations. ${ }^{20}$

Insulin-like growth factor 1 (IGF-1) may mediate the association between BMI and cancer risk. Prospective studies have shown positive associations between IGF-1 levels and risk of non-smoking related cancers, specifically of the breast, ${ }^{21}$ prostate, ${ }^{22}$ and colon/rectum. ${ }^{23}$ Over-nutrition in early life may be associated with both high BMI and high IGF-1 levels, as hepatic IGF-1 production is partially determined by nutritional intake. Indirect support for this hypothesis comes from the observation that leg length in childhood, which may partially reflect IGF-1 levels, is also associated with cancer risk. ${ }^{12}$ Although in this study we have no measures of IGF-1, this mechanism could potentially underlie our results.

Noticeable in this study is the gender difference in the strength of the relation between BMI and mortality from cancers not related to smoking. A possible explanation may be the difference between the sexes in the sites of these cancers. In women, most are sex-hormone related (breast and ovary), whereas in men the majority are colorectal. Although the major source of oestrogens in pre-menopausal women is the ovary, adipose tissue is a secondary source of these hormones. High circulating levels of oestrogens coupled with low luteal phase progesterone levels in women with high BMI may put these women at increased risk of hormone dependent cancers. ${ }^{24}$

\section{Conclusions}

This paper provides further evidence that events which occur in early life may impact on future disease. Without repeated anthropometric measures from various stages of the lifecourse, it is not possible to determine which of the disease pathways outlined above is the most likely. From a public health perspective, however, the relation between BMI in early life and cancer mortality over a 40 year follow up period is important in itself. The increasing prevalence of childhood obesity may result in increased cancer mortality in future years. Early adulthood may provide an opportunity during which health behaviours such as dietary and exercise patterns may be more amenable to change than in later life, and impact beneficially on future health.

\section{Authors' affiliations}

M Okasha, G Davey Smith, Department of Social Medicine, University of Bristol, Bristol, UK

P McCarron, Department of Epidemiology and Public Health, Northern Ireland Cancer Registry, The Queen's University of Belfast, Belfast, UK J McEwen, Department of Public Health, University of Glasgow,

Glasgow, UK
Funding: the authors would like to acknowledge the financial support of the Stroke Association, Chest Heart and Stroke, Scotland, NHS R\&D CVD Programme and the World Cancer Research Fund. This work was undertaken while Mona Okasha was funded by an MRC Studentship.

Conflicts of interest: none.

\section{REFERENCES}

1 Mokdad A, Serdula M, Dietz W, et al. The spread of the obesity epidemic in the United States, 1991-1998. JAMA 1999;282:1519-22.

2 Prentice A, Jebb S. Obesity in Britain: gluttony or sloth? BM 1995:311:437-9.

3 Allebeck P, Bergh C. Height, body mass index and mortality: do social factors explain the association? Public Health 1992;106:375-82.

4 Nieto F, Szklo M, Cornstock G. Childhood weight and growth rate as predictors of adult mortality. Am J Epidemiol 1992;136:201-13.

5 Gunnell D, Frankel S, Nanchahal K, et al. Childhood obesity and adult cardiovascular mortality: a $57-y$ follow-up study based on the Boyd Orr cohort. Am J Clin Nutr 1998;67:1111-18.

6 Must A, Willett W, Dietz W. Remote recall of childhood height, weight and body build by elderly subjects. Am J Epidemiol 1993;138:56-64.

7 Lee I-M, Paffenbarger R. Quetelet's index and risk of colon cancer in college alumni. J Natl Cancer Inst 1992;84:1326-31.

8 Whittemore A, Paffenbarger R, Anderson K, et al. Early precursors of site-specific cancers in college men and women. J Natl Cancer Inst 1985:74:43-51.

9 Must A, Jacques P, Dallal G, et al. Long-term morbidity and mortality of overweight adolescents. A follow-up of the Harvard Growth Study of 1922 to 1935. N Engl J Med 1992;327:1350-5.

10 Hoffmans $M$, Kromhout D, De Lezenne Coulander C. Body mass index at the age of 18 and its effects on 32-year mortality from coronary heart disease and cancer. J Clin Epidemiol 1989;42:513-20.

11 McCarron P, Davey Smith G, Okasha M, et al. Life course exposure and later disease: a follow-up study based on medical examinations carried out in Glasgow University (1948-1968). Public Health 1999:113:265-71.

12 Gunnell D, Davey Smith G, Holly J, et al. Leg length and risk of cancer in the Boyd Orr cohort. BMU 1998;317:1350-1.

13 The Scottish Office. Scottish Health Survey, 1995. Edinburgh: The Scottish Office.

14 Huang Z, Hankinson S, Colditz G, et al. Dual effects of weight and weight gain on breast cancer risk. JAMA 1997;278:1407-11.

15 Barnes-Josiah D, Potter J, Sellers T, et al. Early body size and subsequent weight gain as predictors of breast cancer incidence (lowa, United States). Cancer Causes Control 1995;6:112-18.

16 Van den Brandt P, Dirx M, Ronckers $C$, et al. Height, weight, weight change, and postmenopausal breast cancer risk: the Netherlands Cohort Study. Cancer Causes Control 1997;8:39-47.

17 Trichopoulos D. Hypothesis: does breast cancer originate in utero? Lancet 1990;335:939-40.

18 Durnin J. The change in body weight of a young adult human population after an interval of 15 years. J Physiol (Lond) 1968;198:22P.

19 Albanes D. Total calories, body weight and tumour incidence in mice. Cancer Res 1987;47:1987-92.

20 Frankel S, Gunnell D, Peters T, et al. Childhood energy intake and adult mortality from cancer: the Boyd Orr Cohort Study. BMW 1998;316:499-504.

21 Hankinson S, Willett W, Colditz G, et al. Circulating concentrations of insulin-like growth factor-l and risk of breast cancer. Lancet 1998:351:1393-6.

22 Chan J, Stampfer M, Giovannucci E, et al. Plasma insulin-like growth factor-1 and prostate cancer risk: a prospective study. Science 1998;279:563-6.

23 Ma J, Pollak M, Giovannucci E, et al. Prospective study of colorectal cancer risk in men and plasma levels of insulin-like growth factor (IGF)-1 and IGF-binding protein-3. J Natl Cancer Inst 1999;91:620-5.

24 Pike M, Spicer D, Dahmoush L, et al. Estrogens, progestogens, normal breast cell proliferation and breast cancer risk. Epidemiol Rev 1993;15:17-35. 